\title{
Alta comedia, realismo y novela en Alarcón.
}

IGNACIO-JAVIER LOPEZ

Universidad de Virginia

Al estudiar la novela del XIX se tiende generalmente a establecer clasificaciones en función de rasgos generales del estilo de un autor dado, olvidando sin embargo las variaciones y, especialmente, las distintas tentativas que se dan en el conjunto de la obra de tal autor. Este hecho es particularmente llamativo en el caso de Alarcón, novelista que es definido en función de la novela de tesis, en particular El escándalo (1875), en tanto que esta novela permite contrastar al novelista guadijeño con sus contemporáneos, particularmente con Galdós. Se pierde, no obstante, la perspectiva de algunos intentos suyos singularmente originales; tal es el caso de El capitán Veneno, novela que ha sido ignorada por la crítica, o que ha sido comúnmente relacionada con El sombrero de tres picos a pesar de algunas diferencias notables de estilo que existen entre ambas novelas. El propósito del presente trabajo es dar una descripción de El capitán en función del contexto en que aparece, intentando de este modo distinguir su especificidad frente a las otras obras del autor.

En un magnífico artículo sobre El escándalo, Gullón ha resumido el procedimiento alarconiano del siguiente modo: «El autor suspende a los personajes sobre el resto de los mortales, o dicho en otras palabras, los presenta en relieve, de modo que sin sacarlos de la realidad, 
ésta no los ensucie» ${ }^{1}$. Puede decirse que esta definición es formalmente exacta por lo que se refiere a El escándalo; de hecho, adquiere su fundamento en el primer capítulo de la novela, en el que Fabián Conde, subido al pescante de un carro, sale del barullo carnavalesco de la Puerta del Sol en el día de San Juan. Sin embargo, esta definición ha de alterarse sustancialmente a la hora de estudiar otras obras de Alarcón y, en particular, El capitán Veneno (1881); en esta novela el autor no suspende a los personajes sobre la realidad, sino que simplemente los retira de la misma, introduciéndolos en un interior aislado, encerrándolos.

Para entender correctamente el cambio que se produce entre las dos novelas de Alarcón mencionadas y, consiguientemente, en el modus operandi del escritor hacia 1881, conviene recordar que con la publicación de La desheredada de Galdós se acaba con la novela de tesis y, hecho particularmente importante para el análisis de El capitán Veneno en su contexto adecuado, se propone un tipo de novela radicalmente novedo$\mathrm{so}^{2}$. Como alternativa a esta novedad galdosiana cabe entender esta novela de Alarcón, y es posible explicar su diferencia respecto a otras obras anteriores del autor.

El capitán Veneno se inicia con una selección de tiempo y espacio, precisándose un momento histórico significativo: «La tarde del 26 de marzo de 1848 hubo tiros y cuchilladas en Madrid entre un puñado de paisanos, que, al expirar, lanzaban el hasta entonces extranjero grito de iViva la República!, y el Ejército de la Monarquía española (traído o creado por Ataúlfo, reconstituido por don Pelayo y reformado por Trastamara), de que a la sazón era jefe visible [ ... ] don Ramón María Narváez» ${ }^{3}$. Ahora bien, precisando el contexto histórico anterior, el autor inmediatamente comienza a evadirse de la historia general con el fin de presentar la historia particular. Así dice: «Y basta con esto de historia y de política, y pasemos a hablar de cosas menos sabidas y más

1 G. Gullón, La novela como acto imaginativo, Madrid, Taurus, 1983, pp. 43-4.

2 He intentado detallar este aspecto en mi estudio «Humor y decoro en El capitán Veneno de Pedro Antonio de Alarcón», Boletín de la Real Academia Española (en prensa). Sobre el fin de la novela de tesis, vid. L. Alas, Galdós, Madrid, Renacimiento, 1912, pp. 95-113, y J. Oleza, La novela del XIX: del parto a la crisis de una ideología, Valencia, Bello, 1976, p. 25.

3 Pedro Antonio de Alarcón, El capitán Veneno, en Obras completas, Madrid, Fax, 1943. Todas las citas de las obras de Alarcón remiten a esta edición; se indica el número de página entre paréntesis. 
amenas, a que dieron origen o coyuntura aquellos lamentables acontecimientos» (Capitán, 714; sub. mío).

El procedimiento alarconiano indicado en el párrafo anterior parece acercarse al usado en $E l$ sombrero de tres picos, donde el narrador dice: «Y aquí termina todo lo que la presente historia tiene que ver con la militar y política de aquella época» (Sombrero, 445). Sin embargo, este paralelo es tan sólo aparente, pues, mientras que en El capitán hay una clara retirada de la realidad histórica (cuyos acontecimientos, al fin y al cabo lamentables, motivan la historia particular), en El sombrero el autor lleva a cabo la operación contraria: desea contextualizar la historia particular, integrarla en la general. Así, en el capítulo titulado «De cuando sucedió la cosa», escribe: «Nuestro único objeto, al referir lo que entonces sucedía en el mundo, ha sido venir a parar a que el año de que se habla (supongamos que el de 1805) imperaba todavía en España el antiguo régimen en todas las esferas de la vida pública y particular, como si, en medio de tantas novedades y trastornos, el Pirineo se hubiese convertido en otra Muralla de la China» (Sombrero, 445). En suma, en la novela de 1874 Alarcón presenta de qué modo el tío Lucas y su mujer se integran en una sociedad semifeudal de diezmos y primicias, pero en la que el paternalismo del antiguo régimen impone su armonía en lo público y en lo privado; el Pirineo sirve de muralla para mantener fuera la amoralidad foránea. En la novela de 1881, en cambio, el autor retira a sus personajes de la cambiante realidad histórica, de los lamentables acontecimientos de ésta, y los encierra en un entorno hogareño aislado del mundo exterior; no en vano el extranjero republicanismo se ha manifestado por las calles céntricas de Madrid ${ }^{4}$. Nótese, en fin, que esta oposición entre la paz interior y el bullicio exterior que caracteriza el mundo de los personajes de la novela es presentada por Alarcón como característica del presente y aparece ya en el prólogodedicatoria de la novela a Tamayo; Alarcón deja bien claro que escribe desde la sosegada villa de Valdemoro, cercana a Madrid, y que está a punto de regresar a la corte que, por implicación, puede entenderse como bulliciosa - Cf.: «Hace algunas semanas que, entreteniendo nues-

4 A este respecto, Dendle escribe: «The Catholic attitude can only be described as one of fear: fear of the present, fear of the city, fear of the alien ideas», B. J. Dendle, The Spanish Novel of Religious Thesis, 1876-1936, Princeton UP, 1968, p. 21. Comentando esta cita, J. Oleza, La novela, cit., lug. cit., escribe: «Así aparece esta sensación de atemporalidad tan frecuente en el lector de Alarcón [ ... ] Lo malo llega de fuera, es extranjero y arraiga en Madrid, la gran ciudad». 
tros ocios caniculares en esta sosegada villa de Valdemoro, de donde ya vamos a regresar a la vecina corte» (Capitán, 714).

La característica de entorno hogareño de El capitán motiva el esquema pseudo-realista de la novela, esquema cuyos orígenes pueden buscarse en la alta comedia de la época: un interior de clase alta, con marqueses y condes y una serie de problemas excepcionales para los que, por necesidades convencionales, la solución está dada desde el comienzo. En otras palabras, el lector no tiene grandes dificultades en descubrir que el héroe se va a casar con la heroína, como manda la convención, porque éste es el único desenlace al que puede arribarse con el enredado diálogo que el capitán y Angustias mantienen en la parte cuarta de la novela. El capitán lo deja bien claro en el capítulo II de esta cuarta parte, al afirmar: «Créame usted, Angustias; ni usted es una extraña para mí, ni yo lo soy para usted» (Capitán, 741). Por otra parte, el esquema de alta comedia en que se basa la novela es determinante de la división de los personajes en positivos y negativos: los positivos integran la acción; los negativos, por el contrario, irrumpen en ella, perturbando la armonía de los primeros. Ejemplo de ello es el republicano que, sin ton ni son, dispara un trabucazo a Angustias en la primera parte de la novela. De este republicano había dicho Angustias que era «un hombre muy feo» (Capitán, 716), por lo que, en la lógica convencional de la novela, no extraña que tan feo republicano dispare a la heroína un «alevoso trabucazo» (Capitán, 717). Más aún, para aumentar el efecto de maldad, a causa del alevoso disparo doña Teresa va a caer en tal estado de postración y abatimiento que, al próximo envite de la realidad, acabará por morir. El narrador no se olvida de indicarlo, bien directamente («Según iremos viendo, la infeliz guipuzcoana no había de gozar hora de salud desde aquel espantoso día», Capitán, 717), bien por boca del personaje mismo («iAsí esta fatiga me permitiese a mí bromear también!», Capitán, 728).

El siguiente envite de la realidad es, obviamente, el desenlace del pleito. Si en el capítulo en el que se relata el incidente anterior, titulado «Trabucazo», la realidad exterior irrumpía bruscamente en la vida particular de los personajes, perturbando su armonía, el desenlace del pleito, presentado en el capítulo «Peripecia», viene a mostrar un giro de la acción en un sentido infortunado ${ }^{5}$. El autor, por su parte, se lo re-

5 Sobre la peripetia como inversión de la acción en un sentido infortunado vid. $\mathrm{H}$. Lausberg, Manual de retórica literaria, Madrid, Gredos, 1976, vol. II, pp. 488-9. 
cuerda convenientemente al lector: «El tan celebrado y jubiloso día en que se levantó el Capitán Veneno había de tener un fin asaz lúgubre y lamentable» (Capitán, 732). Lo anterior muestra que el procedimiento usado por Alarcón en El capitán es muy diferente del aparecido en El escándalo. Según indica atinadamente Gullón, en esta novela el autor suspende a los personajes sobre la realidad para que ésta no los ensucie; pero, es preciso notar, la realidad no ha sido eliminada de la novela. En El capitán, en cambio, el autor concibe la realidad de un modo tan limitado (en tanto que es tan sólo elemento perturbador de la armonía que caracteriza la vida particular de los personajes), que éstos están incapacitados para moverse en ella: el autor los mantiene aislados, retirados en un reducido espacio interior de características teatrales. De hecho, el lector no tiene acceso más que al salón de la casa y a un dormitorio contiguo; todo lo demás, como en el cartón pintado de un teatro, ha de asumirse más allá del decorado ${ }^{6}$. Así, cuando Angustias sale a la calle, en el capítulo $\mathrm{V}$ de la primera parte, el lector la percibe a través de doña Teresa y de Rosa, la criada, que la observan por la ventana del salón, como antes observaron el tiroteo en la calle de Preciados; el lector, en fin, no tiene la oportunidad de aventurarse más allá del mencionado salón.

Uno de los elementos que parece aportar realidad a la novela es la retórica cuartelera del capitán: en función de ella aparece un mundo diferente del interior hogareño de las Barbastro. Este hecho fundamenta el choque inicial: al salir de su desmayo el capitán exclama «¿Dónde diablos estoy?» (Capitán, 718; sub. mío), expresión cuya supuesta crudeza espanta a la bondadosa doña Teresa. Más tarde, las referencias del capitán a su formación cuartelera y a su forma de ser, basada en esta experiencia, sirven para acrecentar la oposición entre el soldado y el aislado mundo de las Barbastro. A ello se refiere el capitán cuando dice: «He procurado siempre no tratar con mujeres, ni con niños, ni con santurrones, ni con ninguna otra gente pacífica y dulzona [ ... ] Yo soy un hobre atroz» (Capitán, 720). Finalmente, esta oposición permite superar la ridícula situación que podría generarse en algunas situa-

6 Aunque la comparación es injusta, dada la gran diferencia que existe entre las dos novelas comparadas, recuérdese la casa de doña Lupe, en Fortunata y Jacinta, donde hay cocina y en ella se ve a Papitos, a Rubín y a su hernano, así como a doña Lupe misma. En El capitán se mencionan comidas, caldos, sopas, etc., pero en ningún momento hay mención alguna de la cocina. Tan sólo el salón de la casa y una habitación están en el ángulo de visión del lector. 
ciones particulares, como el momento en que madre e hija discuten si habrá o no necesidad de enarenar la calle de Preciados para que el trajín de los carros no moleste al convaleciente capitán. Ante esto, el capitán, furioso, contesta: «iA mí enarenarme la calle! ¿Soy yo acaso militar de alfeñique para que se me trate con tantos mimos y ridiculeces? (Capitán, 723). Con ello, en suma, puede decirse que el capitán aporta en su hosquedad ingredientes que proceden de un mundo exterior al hogar de las Barbastro; esto es, que proceden de un Madrid que cambia vertiginosamente fuera de las paredes de dicho hogar y en el que, al fin y al cabo, ha recibido $\mathrm{D}$. Jorge sus heridas y ha desempeñado un importante y valeroso papel.

Ahora bien, a pesar de todo, la experiencia cuartelera del capitán no puede aceptarse más que como lo que realmente es: un sucedáneo de realidad, limitado por un convencionalismo que sigue de cerca el modelo de la alta comedia decimonónica; y, como tal, es lo que hay que contradecir en el desenlace. Considérese, a este respecto, el ejemplo de El hombre de mundo de Ventura de la Vega, prototipo de este género de comedia. Así pues, como el D. Luis de El hombre de mundo, el capitán tiene una actitud claramente errónea, resultado de una mala experiencia anterior. Así, a su amplia experiencia de hombre de mundo debe éste su escepticismo en lo referente a la virtud de la mujer, hecho al que alude el personaje directamente cuando, al comienzo de la obra habla de las mil mentiras que en el mundo ha visto (Cf. El hombre de mundo I, 3, vv. 139-140). La experiencia del capitán, por su parte, es resultado de su orfandad y de haberse criado sin cuidados maternales de ningún tipo (Cf. Capitán, 725). Debido a ello, el personaje alarconiano se muestra como un ser hosco y manifiesta un odio irracional por las muestras de cariño.

La experiencia del capitán es obviamente mucho más limitada que la del D. Luis de Ventura de la Vega. Por ello surge una de las más llamativas diferencias entre los dos: mientras que $\mathrm{D}$. Luis se mantiene dentro de los límites del buen tono burgués, el capitán llega a la exageración cómica e, incluso, al absurdo - Cf.: «¡No sé por qué ley de mi naturaleza prefiero que me peguen un tiro a que me traten con bondad!» ( $\mathrm{Ca}$ pitán, 720). Como es obligatorio en la alta comedia, D. Luis aprende su lección al final de la obra, pero, y esto es particularmente diferente de lo que ocurre con el capitán, aquél no es rebajado cómicamente en el desenlace; esto es, el enredo pudo haber tenido elementos cómicos, pero el desenlace carece de ellos y $\mathrm{D}$. Luis sigue siendo el buen burgués 
que era al comienzo. Lo único que cambia es su actitud. Haciendo alusión directa a las escépticas palabras pronunciadas por el personaje al comienzo, su mujer, Clara, enuncia la moraleja en el desenlace:

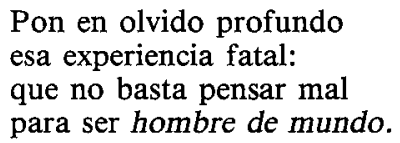

(El hombre del mundo IV, 19, vv. 2922-2925).

Por su parte, el capitán, que había manifestado inicialmente su recelo contra mujeres y niños (Cf. supra), es presentado en la escena final jugando al burro con sus hijos en el salón de su casa matrimonial. Como en el caso de la moraleja de la comedia, la escena final de la novela alude directamente a la exposición inicial. Pero, a diferencia de lo que ocurre con D. Luis, el capitán es rebajado cómicamente, rebajamiento que no es más que la culminación de la comicidad que ha caracterizado al personaje en su dialogo con Angustias en la parte cuarta de la novela.

No es difícil determinar por qué Alarcón se sintió interesado por el modelo de la alta comedia de la época, aspecto este sobre el que se volverá inmediatamente. Más hipotética, sin embargo, es la relación directa entre El capitán Veneno y El hombre de mundo. Sin embargo, conviene considerarla plausible por un momento y recordar que en el mismo año en que aparece El capitán Veneno, Valera publica un magnífico estudio sobre Ventura de la Vega ${ }^{7}$. La amistad existente entre Valera y Alarcón, y el interés que este último muestra por escritores afines a él ideológicamente permiten suponer que debió de conocer dicho estudio - nótese, en este sentido, que Alarcón dedica el volumen de sus Novelas cortas a Valera en su edición en libro de 1881, recordando (y agradeciendo) lo escrito por Valera sobre El niño de la Bola (Cf. Novelas cortas, 105).

El estudio de Valera sobre Ventura de la Vega tiene interés porque en él, al hacer la semblanza del autor, Valera apunta una serie de características que hubieron de ser llamativas para Alarcón. Lo primero que hubo de atraer a éste fue la valoración de El hombre de mundo por Valera, quien señala que, aunque esta comedia es cualitativamente inferior a la tragedia La muerte de César del mismo autor, esta última obra

7 «Ventura de la Vega» en J. Valera, Obras completas, Madrid, Aguilar, 1961, vol. II, pp. 571-88. 
está más comprometida ideológicamente $\mathrm{y}$, por consiguiente, no extraña la general preferencia del público por la comedia. Así dice Valera: «Si bien el arte es el arte, y no se ha de medir por la lección moral, política y religiosa que de él se infiera, todavía es lección poco simpática la de que conviene que el tirano destruya la libertad cuando el pueblo no la merece [como ocurre en La muerte de César], mientras que la moraleja matrimonial, amorosa y casera de El hombre de mundo no se hallará persona a quien desagrade» (Valera, Ventura, 580; vid., también, pp. 578-9). En segundo lugar, y centrándose en las perfecciones formales de la comedia, Valera señala el respeto que el autor ha guardado al decoro en la presentación de los personajes, indicando: «Dichas personas [ ... ] tienen el decoro que su clase exige. Salvo el defecto que el poeta en ellas critica, deben aparecer en la escena no sólo en conformidad con la vida real, sino en conformidad también con cierto ideal de la vida, que hasta en los modales se muestra y se llama buen tono» (Valera, Ventura, 581). Finalmente, un último aspecto que hubo de resultar atractivo para Alarcón había de ser aquel que se refiere al temperamento independiente de Ventura de la Vega y más concretamente a su posición en medio del mundo romántico: como Alarcón había de proponer en sus escritos doctrinales, Ventura de la Vega buscó sus raíces en los clásicos españoles, frente al gusto francés entonces imperante entre los escritores románticos (vid. Valera, Ventura, 576).

Alarcón hace uso del modelo de comedia de salón o alta comedia en $E 1$ capitán Veneno con el fin de mostrar ias posibilidades de un tipo de novela radicalmente diferente del aparecido en las muestras de novela renovada del momento. En este sentido, el correcto entendimiento de la novela de Alarcón ha de tener en cuenta que esta novela aparece pocos meses después de que se publicara La desheredada de Galdós. Ha de añadirse ahora que la historia de Angustias, protagonista de EI capitán, guarda extraordinarios parecidos temáticos con la de Isidora Rufete, protagonista de La desheredada, en particular dado que ambos personajes dicen ser miembros de la aristocracia, pertenencia que no es reconocida públicamente, quedando pendiente la decisión final, en ambos casos, del resultado de un pleito que en ambos casos culmina del mismo modo, aunque las protagonistas tengan un desenlace radicalmente diferente (Cf. referencia de la nota 2 ).

Ahora bien, este parecido no debe oscurecer un hecho más importante aún: mientras que la novela galdosiana se centra en la historia de la protagonista, El capitán Veneno oculta esta historia y desvía el cen- 
tro de interés hacia la comedia de salón. La razón de esta desviación es obvia si se atiende a la posición alarconiana: La desheredada es un nuevo tipo de novela caracterizada por presentar una historia que, para Alarcón, no sólo rompe con el decoro o buen tono, sino que además rechaza la función de entretener que había caracterizado hasta entonces al género novelesco. Este rechazo había sido expresado de modo patente en los trabajos teóricos de los jóvenes escritores, quienes consideran que la novela ha dejado de ser pasatiempo fugaz para convertirse en vehículo de reflexión y conocimiento ${ }^{8}$. Por otra parte, esta idea está desarrollada de modo implícito en La desheredada misma; las dedicatorias inicial y final sirven a este propósito. Ante esto, Alarcón se propone rescatar el lugar propio del género; o sea, presenta una historia particular con un problema decoroso, también particular, que se resuelve finalmente de un modo armónico, todo ello desarrollado sobre la base del entretenimiento que procura el enredado argumento. Por esto, en fin, debe insistirse en el hecho de que, en EI capitán Veneno, Alarcón, consciente del valor de su capacidad inventiva, propone una historia amena, convenientemente enredada, como prototipo de novela. O en otras palabras, frente a los ejemplos de novela renovada, el propósito de Alarcón es mostrar el potencial que encierra un modelo tradicional de novela y por ello transforma aquellos elementos argumentales de La desheredada que resultan conflictivos o, si se prefiere, que no se adecuan a su entendimiento del género, lo cual hacer surgir la gran diferencia de El capitán Veneno con novelas anteriores como El escándalo. Para repetir la analogía con la obra de Ventura de la Vega, antes propuesta, el autor se interesa por el modelo de la alta comedia porque, frente a obras cualitativamente superiores, pero ideológicamente tan comprometidas como El escándalo, se preocupa ahora de la invención y se centra en la amenidad y el entretenimiento que la novela ha de procurar.

Al proponer al lector una historia cuya finalidad es ser amena, el autor manfiesta explícitamente los límites de la misma. Su propósito parece ser forzar al lector a ser consciente de que dichos límites son rigurosamente necesarios para conseguir el objetivo propuesto; esto es,

8 E. Pardo Bazán, «Prefacio» a Un viaje de novios, Barcelona, Labor, 1971, pp. 57-62. Asimismo, vid. L. Alas, «El libre examen y nuestra literatura presente», en Solos de Clarín, Madrid, Alianza, 1971, pp. 65-78, y su reseña a La desheredada recogida en L. Alas, Galdós, cit., lug. cit.; y J. Ortega Munilla en R. Schmidt, José Ortega Munilla y sus novelas, Madrid, Revista de Occidente, 1973, pp. 179-96. 
ser ameno ${ }^{9}$. El primer ejemplo de dichos límites es, obviamente, la ya mencionada separación de historia socio-política e historia particular, que se da al comienzo de la novela. Asimismo, inmediatamente después, el autor vuelve a repetir lo mismo en la presentación de Angustias: «No era, no (o por mejor decir, no quería ser) una de esas beldades llamativas, aparatosas, fulminantes, que atraen todas las miradas no bien se presentan en un salón, teatro o paseo, y que comprometen o anulan al pobrete que las acompaña» (Capitán, 715; sub. mío). No se puede evitar el pensar que hay aquí una referencia directa a La desheredada: en el capítulo XVII de la primera parte de esta novela («Igualdad. Suicidio de Isidora»), la protagonista galdosiana se pasea por las calles de Madrid después de haber sido rechazada por la Marquesa de Aransis. En las calles, entre el bullicio de la gente, Isidora se entera de los importantes acaecimientos sociales y políticos del día: el rey se va y llega la I República. Acompañada por D. José Relimpio, la protagonista llega a los jardines cercanos al Palacio de Oriente y allí pide a D. José que regrese a casa y la deje sola; éste responde: «No, hija, no. No puedes andar sola de noche. Estás cada día más guapa, y por dondequiera que vas llamas la atención. - ‘iLlamo la atención!’, pensó ella, y se levantó decidida» (La desheredada I, xvii, 1077) ${ }^{10}$. Finalmente, como se sabe, Isidora, desoyendo las súplicas y preguntas de su padrino, el «pobrete» D. José, se encamina hacia las Cortes donde se va a entregar al Marqués de Saldeoro.

Considerado, por tanto, el obvio contraste que existe entre Angustias e Isidora, es más fácil determinar la operación alarconiana: a diferencia de Isidora, Angustias no es llamativa (no quiere serlo). El paréntesis hace especialmente patente la posición de Alarcón: en función de él se previene que el personaje quede expuesto a la realidad, la cual se concibe de un modo muy limitado en tanto que elemento perturbador

9 Esta necesidad de los límites de la novela se halla manifiestamente explícita, a posteriori, en su «Discurso sobre la oratoria sagrada», del año 1883, en el que Alarcón hermana la bondad, la belleza y el buen gusto del lector, diciendo: «Agradezco, pues, al Sr. Pidal, y también a ciertos modernos escritores franceses, la justificación que han hecho de mis opiniones, el uno autorizándolas con su dictamen y con tan importantes citas, y los otros comprobándolas ad absurdum; quiero decir, apestando y sublevando a todas las personas de buen gusto y buenas costumbres con obras realistas o naturalistas en que anda la verdad a la greña con la belleza, o la belleza divorciada de la bondad» («Oratoria sagrada» 1768; sub. mío).

10 B. Pérez Galdós, La desherédada, en Obras completas, Madrid, Aguilar, 1975, Vol. I. Salvo indicación contraria, todas las citas del texto remiten a esta edición. 
de la armonía que caracteriza al mundo privado de los personajes. Por ello, está claro que acabaría por erosionar al personaje. De ahí que Angustias sea presentada como arquetipo de virtudes y, especialmente como modelo de mujer perfecta para ser esposa: bella, virtuosa y hogareña. El autor continúa indicando que Angustias «era un conjunto sabio de perfecciones físicas y morales, cuya prodigiosa regularidad no entusiasmaba al pronto, como no entusiasman la paz y el orden» (Capitán, 715). Si se considera ahora que en la calle de Preciados se baten a tiros monárquicos y republicanos, no extrañará que el modelo de armonía creado por Alarcón sea mantenido en el interior del hogar: a diferencia de Isidora, cuya historia corre paralela con la agitación social del momento de la I República, Angustias está a salvo del torbellino de acontecimientos del exterior; si la primera se mezcla o, mejor, se expone a la realidad exterior, la segunda permanece aislada en su casa, de donde sale excepcionalmente (en dos ocasiones: la primera para buscar a un médico que cure a D. Jorge; la segunda, a rezar una salve a la Virgen en una iglesia cercana); si Isidora, en fin, se pierde y acaba en prostituta, despeñándose «en el vertiginoso laberinto de las calles» (La desheredada II, xxviii, 1180), Angustias acaba casándose con D. Jorge de Córdoba. Nótese, en fin, un contraste adicional: frente al movimento general de la primera República que aparece en La desheredada, Alarcón presenta un oscuro altercado entre francotiradores republicanos y las fuerzas del orden vigente. De este modo, mientras Isidora es literalmente arrastrada por el bullicio social, Angustias es situada por encima de una algazara republicana aislada.

Por otra parte, el modelo teatral elegido por Alarcón puede considerarse como una tranforinación consciente del modelo galdosiano. En efecto, en la primera edición de La desheredada ${ }^{11}$ Galdós usa un marco teatral para presentar su «comedia humana», marco que se hace explícito en la nómina de personajes que se añade a cada una de las partes de la novela:

PERSONAJES DE ESTA PRIMERA PARTE

Isidora Rufete, protagonista

Mariano Rufete, su hermano.
PERSONAJES DE ESTA SEGUNDA PARTE Isidora Rufete, protagonista.

Mariano Rufete, su hermano.

11 B. Pérez Galdós, La desheredada, Madrid, Administración de La Guirnalda y Episodios nacionales, [1881]. 
La Sanguijuelera, tía.

Augusto Miquis, estudiante de Me- Augusto Miquis, doctor en Medicina dicina.

Joaquín Pez, marqués viudo de Joaquín Pez.

Saldeoro.

D. Manuel José del Pez, Dtor. gral.

en el Ministerio de Hacienda.

D. José de Relimpio y Sastre, espejo de los vagos.

D. José de Relimpio y Sastre, tenedor de libros.

Doña Laura, su esposa

Emilia de Relimpio de Castaño.

Melchor de Relimpio

Emilia

Leonor

hijos. D. Alejandro Sánchez Botín, Padre de la Patria

La Marquesa de Aransis.

Juan Bou, litógrafo.

El Majito, niño.

Juan José Castaño, ortopedista.

Zarapicos y Gonzalete, pícaros.

Tomás Rufete.

El señor de Canencia.

Muñoz y Nones, notario.

Madama Eponina, modista.

Riquín, niño.

Matías Alonso, conserje de la ca- Modesto Rico, tratante en vinos. sa de Aransis.

Un concejal.

Palo-con-ojos.

Un comisario de Beneficencia.

Gaitica.

Mi tío el Canónigo (que no sale). Diversos peces.

Diversos pájaros.

Un gran personaje (que no habla).

Diversos personajes (que no hablan tampoco).

Hombres y mujeres del pueblo, Un abogado, testigos, carceleros Peces de ambos sexos, criados, y carceleras, curiales, un oficial guardias civiles, etc. de litografía, hombres y mujeres del pueblo, porteros, tropa, etc. 
La escena es en Madrid y empieza en la primavera de 1872 .
La escena es en Madrid y principia en diciembre de 1875 .

(ed. cit. p. 254)

Esta nómina se elimina en posteriores ediciones de La desheredada, pero lo importante es que está en la primera y que Alarcón la tuvo muy en cuenta. De ahí que, transformando la comedia humana galdosiana, cuando el novelista guadijeño aluda a un modelo teatral, habrá de aludir a un modelo convencional (i.e., la alta comedia de la época) cuya característica, como manifiesta Valera al estudiar El hombre de mundo de Ventura de la Vega, es el decoro y el buen tono; nótese, en particular, que se elimina la mezcolanza de personajes propuesta por Galdós en su hombres, mujeres, carceleros, etc.

El modelo de alta comedia, por otra parte, permite al autor seleccionar los elementos de su novela y, consiguientemente, eliminar de la historia particular de sus personajes aquellos ingredientes que pudieran perturbar la armonía de sus vidas. Un ejemplo de particular interés viene dado en el tratamiento de Tadeo Jacinto de Pajares, el abogado del pleito que doña Teresa mantiene en los tribunales, quien envía una carta a Angustias en el capítulo II de la cuarta parte de la novela. Empleando la técnica teatral de informar al espectador del contenido de una carta mediante la lectura de la misma, Angustias da a leer al capitán la carta de Pajares. En dicha carta es preciso destacar el uso de vocabulario jurídico: extraoficialmente, óbito, legítimo sentimiento, inapelable golpe; incluso cuando el abogado apela a la sinceridad de sus sentimientos, el efecto jurídico de su lenguaje es patente: «Dicho esto, que no es fórmula oratoria de cortesía, sino expresión del antiguo y alegado afecto que le profesa mi alma, tengo que cumplir con usted otro deber sagrado, cuyo tenor es el siguiente» (Capitán, 738).

En la estructura de la novela el estilo jurídico de Pajares contrasta de modo bastante obvio con el humorístico estilo oratorio del Marqués de los Tomillares; incluso los apellidos, en su tosco simbolismo, permiten contemplar dicho contraste entre el oloroso Tomillares y el menestral Pajares. El Marqués aparece en la segunda parte de la novela y, según él mismo informa, es rico y viudo, carece de más heredero que el capitán y por ello aspira a casarle para, según sus propias palabras, tener sucesión para el título de Marqués (Cf. Capitán, 726). Pajares envía su carta en la última parte de la novela (antes había enviado a su 
procurador), en la que manifiesta su interés por Angustias. Es decir, el Marqués llega al mundo de las Barbastro para cumplir una función armónica: morirse y dejar al capitán de heredero de fortuna y título; Pajares, en cambio, no aparece directamente, sino a través de emisarios (i.e., el procurador, la carta), siendo la amenaza del exterior que ronda a la protagonista. Correspondientemente el Marqués cumple su función armónica (i.e., se muere), lo cual es manifiestamente enunciado por el narrador en el último capítulo de la novela: «¿Mi querido Jorge es ya Marqués? [ ... ] ¿Murió al fïn el bueno de don Álvaro?» (Capitán, 744; sub. mío). Pajares, por su parte, llegado del exterior, viene a perturbar la tranquila vida de los personajes hasta que es literalmente eliminado por Angustias; ésta hace pedazos su carta, y pronuncia: «Yo desprecio al abogado con todos sus mal adquiridos millones $[. ..] ; \mathrm{Co}$ barde y avaro, imaginó desde luego que podría hacer suya a una mujer como yo!» (Capitán, 739).

Dos hechos importan en este texto. En primer lugar, la alusión a los orígenes de la riqueza del abogado, cuyos mal adquiridos millones recuerdan al Sánchez Botín de La desheredada. Precisando este parecido, nótese que en el capítulo VI de la segunda parte de la novela galdosiana Joaquín hace burla del estilo oratorio de Botín. Por otra parte, el desprecio que Angustias manifiesta por el abogado recuerda la despectiva réplica de Isidora al senador: «Su dinero de usted no basta a pagarme... Valgo yo infinitamente más (La desheredada II, vii, 1114); $\mathrm{y}$, posteriormente, aludiendo de forma insultante a los orígenes de la fortuna de Botín, Isidora exclama: «Soy la vengadora de los licenciados de Cuba» (Ibíd. 1115). Ahora bien, la mención de los orígenes de la riqueza de Pajares cobra nuevo interés al ser considerada en función del marco histórico de la novela: evidencia de que los tiempos cambian es el tiroteo que cruzan el ejército de la monarquía y los feos republicanos de bandidesco trabuco en el capítulo inicial de la novela. El capitán, como héroe de la novela, se ha mostrado valeroso en la represión de los últimos. De modo similar, según informa el Marqués de los Tomillares, fue firme en meter en cintura a los administradores de éste:

Ocurrióseme, hace siete años, la peregrina idea de nombrarle contador de mi casa y hacienda, rápidamente desvinculadas por la muerte sucesiva de los tres últimos poseedores [ ... ] y muy decaídas y arruinadas a consecuencia de estos mismos frecuentes cambios de dueño [ ... ] Desde aquel día mis asuntos entraron en orden y prosperidad: antiguos e infieles administradores perdieron su puesto o se convirtieron' en santos, y al año siguiente se habian duplicado mis rentas [ ... ] Para realizar tales prodigios, hale bastado a ese tronera con una visita que giró a caballo por todos mis estados (llevando en la mano el sable a guisa de bastón) (Capitán, 726). 
De igual modo, se propone meter en cintura al abogado, cuyos mal adquiridos millones le asemejan al grupo de menestrales que administraban los estados del Marqués. De nuevo vuelve a aparecer el sable de D. Jorge pero, para rebajar más al abogado, es ahora suplantado por las muletas: "iMire usted aquí un abogado a quien yo le voy a cortar el pescuezo! [ ... ] ¡Habrá infame! ¡Habrá judío! ¡Habrá canalla! [ ...] ¡Corro en su busca! ¡A ver! ¡Alárgueme usted esas muletas! [ ... ] iy el sable! ¡Con las muletas me basta y sobra para romperle la cabeza!» (Capitán, 739) ${ }^{12}$.

Angustias detiene al impulsivo capitán, hablando con desprecio de Pajares como el indigno viejo. El tinte moratiniano que cobra Pajares, presentado aquí como el viejo indigno de la joven Angustias, vuelve a remitir esta novela de Alarcón al modelo de la comedia. En este sentido, y para insistir en la relación hipotética entre Alarcón y Ventura de la Vega, previamente señalada, Valera había indicado que «Vega parecía nueva encarnación del espíritu de don Leandro Fernández de Moratín» (Valera, Ventura, 577). Por otra parte, ya antes Rosa, la criada, había aludido a este hecho al indicar que el abogado «es algo más viejo» que D. Jorge (Capitán, 728). Sin embargo, en la cuarta parte de la novela, cuando la amenaza del exterior que supone Pajares se hace más intensa, este dato se intensifica también, aun a riesgo de pecar de incoherente pues, si se dijo que Pajares, definido por Angustias como indigno viejo, es algo más viejo que $\mathrm{D}$. Jorge, pronto se dirá que $\mathrm{D}$. Jorge es «todavía joven» (Capitán, 741). El caso, en fin, es que la reducción moratiniana del problema permite eliminar la amenaza del exterior: Pajares es reducido cómicamente a «indigno viejo» $\mathrm{y}$, de este modo, se orilla un posible enfrentamiento entre él y $\mathrm{D}$. Jorge. Ni que decir tiene que este enfrentamiento obligaría a introducir en la novela un tipo de personaje demasiado vinculado al turbulento exterior, exte-

12 Puede verse en esta presentación de D. Jorge un antecedente del Montenegro de ValleInclán en la serie La guerra carlista. En principio, el capitán que manifiesta que va a cortar el pescuezo al abogado parece anticipar a Montenegro, cuando éste indica que tiene que acercarse al pueblo vecino para apalear a un escribano. Por otra parte, los administradores que engañan al dueño de las tierras aparecen también en dicha serie de Valle-Inclán: Cara de Plata manifestará su odio por este grupo social, indicando a Bradomín que ha de tratarlos con el látigo. La diferencia entre Alarcón y Valle-Inclán, sin embargo, es obvia: mientras que el primero usa esta comicidad para exponer una visión heroica (y nótese que el capitán gira su visita «a caballo» y sable en mano), Valle-Inclán ironiza respecto a las manifestaciones de Montenegro sobre la necesidad de mantener las tradiciones (por ejemplo, apalear escribanos). 
rior que el autor ha eliminado tajantemente al comienzo de la novela. De ahí que Angustias, en bien de la armonía final, literalmente pronuncie la desaparición literaria de Pajares: «No hablemos más, ni ahora ni nunca, del indigno viejo» (Capitán, 739; sub. mío).

En su investigación sobre la recepción de la obra por el lector, Iser ha usado el modelo de la teoría de los actos del habla (Speech Act Theory) desarrollado por Austin, a fin de explicar dicha recepción ${ }^{13}$. Modificando parcialmente la jerarquía de Austin, Iser indica que el lector cuestiona la validez de las convenciones que aparecen en el texto, concluyendo:

In this process the reader is guided by a variety of narrative tecniques, which might be called strategies of the text. These strategies correspond to the accepted procedures of speech acts, in so far as they provide an orientation in the search for intentions underlying the selection of conventions. But they differ from the accepted procedures in that they combine to thwart stabilized expectations or expectations which they themselves have initially stabilized (Iser, Act of Reading, 61).

Iser propone aquí un procedimiento para explicar el desarrollo de la novela dentro del género $\mathrm{y}$, correspondientemente, el desarrollo de expectativas por el lector, a la vez que el cuestionamiento de las mismas por éste. No cabe duda, sin embargo, de que tan sólo la primera parte de las conclusiones de Iser es aplicable a El capitán Veneno: el texto provoca ciertamente una serie de expectativas pero, a diferencia de lo descrito por Iser en el texto anterior, en El capitán estas expectativas se mantienen de modo permanente y en ningún momento cabe la posibilidad de que el lector las cuestione. Precisamente por ello la operación alarconiana se hace particularmente significativa en el contexto de la novela española del período.

Nótese, una vez más, la diferencia que existe a este respecto en el tratamiento de los dos personajes, Isidora Rufete y Angustias Barbastro, en La desheredada y El capitán Veneno respectivamente. Creando expectativas en el lector, el narrador galdosiano pone como epígrafe del capítulo XV de la segunda parte de la novela la pregunta «¿Es o no es?», pregunta que se relaciona con el capítulo XVI de la primera parte, titulado «Anagnórisis». El hecho de que estos capítulos se resuelvan irónicamente ejemplifica de qué modo se destruyen las expectativas previa-

13 W. Iser, The Act of Reading, Baltimore, The John Hopkins UP, 1980, pp. 53-85. 
mente establecidas. Por el contrario, en El capitán Veneno Angustias, que sigue siendo la hija del valeroso general y conde carlista, admite la legalidad que se pronuncia en contra de su «mala causa» (Capitán, 739); no hay aquí rebelión por parte del personaje ni, aun menos, ironía por parte del narrador. Sin embargo, el lector no tiene capacidad para disputar si Angustias es o no condesa de Santurce; esta cuestión ni siquiera se plantea, puesto que en última instancia carece ya de interés: tanto el Marqués de los Tomillares como, más tarde, el capitán han aceptado estos títulos. Angustias, en fin, no es reconocida socialmente como condesa pero, por eso, no deja de ser quien es.

Siguiendo con el problema que plantean las expectativas, ha de notarse que en esta novela existe una estrecha relación entre autor y lector, relación que se sustenta en el uso por parte del narrador de la primera y segunda personas verbales. Precisamente por ello el autor no ofrece sorpresas al lector, sino que le pide total asentimiento. Así pues, si Alarcón ofrece una historia amena al lector, esto es posible en la medida en que dicho lector acepta unos límites dados, los cuales, como se señaló más arriba, son explícitamente enunciados en la novela. Buena prueba de ello es el diálogo que mantienen Angustias y el capitán en la cuarta parte de la novela, diálogo en el que las convenciones de la sociedad son totalmente aceptadas como exigen el decoro y la búsqueda de un desenlace armónico:

— ¡Señor de Córdoba!... - insistió Angustias con mayor acritud-. ¡ Vuelvo a suplicar a usted que preste alguna atención a un caso en que están comprometidas mi honra y mi dignidad!...

- ¿Para mí no tiene usted nada comprometido! —respondió don Jorge [ ...]

- ¡Para mí es usted la mujer más honrada y más digna que Dios ha criado! - No basta serlo para usted! ¡Es necesario que opine lo mismo todo el mundo! ( Capitán, 739).

$\mathrm{Y}$, poco más tarde, todavía de forma más obvia, los personajes cruzan las siguientes palabras: «[Capitán] - ¿Qué me importa a mí la sociedad? - [Angustias] - iA mí me importa mucho! Entre otras razones, porque sus leyes son un reflejo de la ley de Dios» (Capitán, 740). Dado lo anterior, hay que concluir que en esta novela de Alarcón no se rompe con unas expectativas previamente motivadas en el lector, sino que, muy al contrario, la posibilidad de que la novela tenga un desenlace armónico y, por consiguiente, logre el propósito de entretener dentro de los límites del decoro, es posible gracias a que esas expectativas se mantienen: son aceptadas por el autor, por los personajes, $\mathrm{y}$, dado el carácter de lector amigable que supone el uso de las personas ver- 
bales, no se piensa la posibilidad de que el lector pueda rechazarlas -al fin y al cabo, Angustias, quien es «el símbolo [ ... ] del sentido común» (Capitán, 715), deja bien claro que es necesario aceptar las normas sociales, reflejo de la ley de Dios.

Lo anterior permite concluir ahora diciendo que Alarcón se mueve dentro de un tipo muy particular de convenciones, archiconocidas si se quiere, pero que él considera todavía viables. A este respecto conviene detallar en sus propios términos un aspecto antes señalado. Según fuera dicho, El capitán Veneno usa el modelo convencional de la alta comedia. Sin embargo, este hecho, que ha sido considerado de modo negativo en la evaluación de la novela, es precisamente lo que la hace especialmente significativa: hay que insistir en que el autor hace uso de este modelo consciente de su convencionalismo. Prueba de ello es no sólo la división de la novela en cuatro partes (división que reproduce el esquema de las comedias de salón) o el contenido de los epígrafes, sino especialmente el concepto escénico usado por el autor para dar unidad a la mayoría de los capítulos de la novela - como en las piezas dramáticas, la mayoría de los capítulos logran unidad en función del número de personajes que aparecen en los mismos; cuando el número de personajes cambia, el autor cierra un capítulo e inicia otro. Finalmente, si Alarcón hace uso consciente de un modelo convencional, lo hace con un propósito estético bien definido: considerando el ingenio como la facultad principal del novelista, el autor se mueve dentro de unos límites estrechos en función de los cuales demostrar no sólo su particular capacidad inventiva, sino especialmente las posibilidades de un tipo de novela que se ve negada o rechazada por las corrientes renovadoras. A este respecto, el siguiente texto de Clarín, cuyo objeto es La desheredada galdosiana, permite entrever los dos tipos de novela que están en juego:

La novela, si quiere ser imitación de la vida real, en lo que convenimos todos, necesita no tener esos artificiosos nudos y desenlaces, que pueden demostrar mucho ingenio [... ] pero no son esenciales, ni convenientes siquiera, en la obra que tiene por objeto representar con propiedad y exactitud el movimiento de los sucesos sociales. La composición de La Desheredada es peor que la de Gloria, Doña Perfecta, etc., si se adopta el criterio que ha hecho de El tanto por ciento la mejor obra de Ayala; pero [ ... ] si se quiere comprender que la verdad de la narración exige no poner puertas al campo [...] entonces se admira en $L a$ Desheredada la perfecta composición que da a cada suceso sus antecedentes y consecuencias naturales (Alas, Galdós, 110-1).

Este texto de Clarín permite distinguir entre un tipo de novela que se ofrece como obra del entendimiento, La desheredada, y otro cuyo 
fin aparente o inmediato no es el análisis de la realidad, sino la amenidad y, en función de ello, se ofrece como objeto estéticamente válido. En otras palabras, cuando Clarín dice que la novela ha de ser imitación de la vida real, esto es válido para $L a$ desheredada, pero no para $E 1 \mathrm{ca}$ pitán Veneno.

Para concluir, en el análisis anterior se ha querido mostrar de qué modo El capitán Veneno es una novela conscientemente tradicional que el autor presenta al lector en un momento en que la forma tradicional de novelar está amenazada por las corrientes renovadoras de la novela, y corre el riesgo de ser desplazada del sistema literario. Así, si La desheredada supone una superación de la novela de tesis (que deja paso a un nuevo tipo de novela en el que la descripción narrativa, p. ej., prima sobre la opinión autorial, quedando de este modo la ideología subordinada a la observación de la realidad), EI capitán Veneno se separa asimismo de la novela de tesis con el fin de buscar un modelo tradicional de novela. En esta búsqueda de un tipo de novela tradicional, el autor recurre al modelo de la alta comedia decimonónica. En este género el autor encontró una serie de elementos fundamentales: decoro, buen tono, y la posibilidad de una aceptación general por parte de público que otras obras del autor, indudablemente de mayor empeño (como El escándalo), no podían tener por su propio carácter de novelas polémicas. Finalmente, las convenciones impuestas por el género modelo, la alta comedia de la época, determinan una especial relación del autor con el lector, quien está imposibilitado de cuestionar dichas convenciones; el que la novela logre entretener y obtenga un final armónico depende de que el lector respete las convenciones ofrecidas por el autor. 